Article

\title{
Research on Economic Operation Strategy of CHP Microgrid Considering Renewable Energy Sources and Integrated Energy Demand Response
}

\author{
Jun Dong, Shilin Nie, Hui Huang *, Peiwen Yang, Anyuan Fu and Jin Lin \\ North China Electric Power University, Beijing 102206, China \\ * Correspondence: hh@ncepu.edu.cn
}

Received: 23 August 2019; Accepted: 2 September 2019; Published: 4 September 2019

\begin{abstract}
Renewable energy resources (RESs) play an important role in the upgrading and transformation of the global energy structure. However, the question of how to improve the utilization efficiency of RESs and reduce greenhouse gas emissions is still a challenge. Combined heating and power $(\mathrm{CHP})$ is one effective solution and has experienced rapid development. Nevertheless, with the large scale of RESs penetrating into the power system, CHP microgrid economic operation faces great challenges. This paper proposes a CHP microgrid system that contains renewable energy with considering economy, the environment, and system flexibility, and the ultimate goal is to minimize system operation cost and carbon dioxide emissions $\left(\mathrm{CO}_{2}\right)$ cost. Due to the volatility of renewable energy output, the fuzzy C-means (FCM) and clustering comprehensive quality (CCQ) models were first introduced to generate clustering scenarios of the renewable energy output and evaluate the clustering results. In addition, for the sake of improving the flexibility and reliability of the CHP microgrid, this paper considers the battery and integrated energy demand response (IEDR). Moreover, the strategy choices of microgrid operators under the condition of grid-connected and islanded based on environment and interest aspects are also developed, which have rarely been involved in previous studies. Finally, this stochastic optimization problem is transformed into a mixed integer linear programming (MILP), which simplifies the calculation process, and the results show that the operation mode under different conditions will have a great impact on microgrid economic and environmental benefits.
\end{abstract}

Keywords: CHP microgrid; renewable energy resources; integrated energy demand response; economic operation strategy

\section{Introduction}

With the increasing depletion of fossil energy and the deterioration of the environment becoming more and more serious, the development and utilization of RESs is the main direction of future energy development. Distributed energy based on RESs such as wind power, solar energy, and biomass widely exist as clean energy, and development technology is becoming more and more mature, which has received wide attention around the world. Many countries have set future renewable energy development goals to promote sustainable energy development [1].The share of RESs in Finland will increase to $38 \%$ by 2020 [1]. The Chinese government has formulated four energy revolutions, aimed at achieving the goal of nonfossil energy accounting for $15 \%$ and $20 \%$ of primary energy consumption in 2020 and 2030, respectively [2]. Meanwhile, in traditional power systems, a large part (40-60\%) of fossil energy or renewable energy sources may be wasted because traditional power systems cannot effectively use the input energy [3]. Further, the fluctuation of renewable energy output, market electricity prices, and load demand make it hard to elevate comprehensive energy utilization efficiency 
and reduce greenhouse gas emissions. In this regard, one of the effective solutions to solve these problems is the combined heating and power (CHP) microgrid. As an independent and controllable energy supply system, CHP microgrids can satisfy local energy demands and guarantee the safe and stable operation of a power system, reduce extra costs, and improve the environment $[4,5]$. However, with the huge penetration of renewable energy, the operation mode of the CHP microgrid has changed dramatically, which needs a new mode of operation to match the current situation.

The economic dispatch of a CHP microgrid with renewable energy has been the focus of significant efforts in the literature. Reference [6] presents a multiobjective economic emission dispatch to minimize total operation cost and $\mathrm{CO}_{2}$ emission cost for the microgrid that contains RESs. Reference [7] developed an optimization dispatching model for CHP plants to minimize system operation costs and satisfy the end-consumers' demands. For the CHP-direct heating(CHP-DH) system, the authors established energy balance, system control, and operation constraints in [8], where the optimized objective function is to minimize system operation cost and net acquisition for heat and power. A stochastic optimization model considefing the economic and environmental impacts and reliability is proposed in [9], whose ultimate goal is to minimize fuel cost. In order to solve the multiobjective economic dispatch of the microgrid, a particle swarm optimization (PSO) method and enhanced firefly algorithm (FA) have been adopted, respectively, in [10,11]. Reference [12] developed an optimization model from both the environmental and economic viewpoints and proposes optinal operation and management strategy for the mincrogrid. Reference [13] introduces an economic model and optimization method for the CHP system, including solar, wind, and fuel cell. The optimization goal is to minimize system operation costs and maintenance costs and compare the effects of genetic algorithms and particle swarm optimization algorithms in the model. In these references, although the fuel cost and the operation cost of the generator units are taken into account, the impact of environmental on the economic operation of CHP microgrids is rarely considered.

Further, several studies focus on the impact of auxiliary functions, such as demand response and batteries on CHP microgrid operation. Reference [14] satisfies the electrical and thermal load demands of end-users with minimal cost by implementing demand response (DR) programs. Reference [15] considers the energy storage system as a non-ideal battery and analyzes the impact of battery on the economic operation of CHP microgrid. Reference [16] considers DR as a virtual generator, replacing user-side resources with supply-side energy, which can effectively improve energy efficiency and reduce energy costs. References $[17,18]$ believe that under fluctuation of electricity prices, real-time electricity prices can improve the adaptability of DR and thus propose a price-based DR management model for real-time electric and thermal loads. However, most studies about DR focus on the power load but neglect the heat load. Therefore, it is necessary to propose a novel DR model.

In addition, the impact of volatility of renewable energy on grid shocks has not been well resolved. Some of the literature has studied the uncertainty processing method. Reference [19] describes the uncertainty of wind power output through normal distribution but cannot accurately characterize wind power changes. A weighting method is applied to systematically combine multiple predictive models in [20], which can reduce the prediction bias. References [21-24] deal with wind power uncertainty through scenario generation and reduction methods. The solution to the uncertainty of renewable energy output are relatively simple and quite limited. It is urgent to find new ways to reduce the impact of renewable energy output uncertainty on the power system.

Through the analysis of the previous literature, we summarize the structure and influencing factors of the CHP microgrid system proposed in several typical studies and compare them with this paper, as shown in Table 1. 
Table 1. Relevant research review.

\begin{tabular}{|c|c|c|c|c|c|c|c|c|c|c|}
\hline \multirow[t]{2}{*}{ Authors } & \multicolumn{2}{|c|}{$\begin{array}{l}\text { Energy } \\
\text { Demand }\end{array}$} & \multicolumn{4}{|c|}{ System Components } & \multirow[t]{2}{*}{ IEDR } & \multirow{2}{*}{$\begin{array}{c}\text { Grid- } \\
\text { Connected }\end{array}$} & \multirow{2}{*}{$\begin{array}{c}\mathrm{CO}_{2} \\
\text { Emission }\end{array}$} & \multirow{2}{*}{$\begin{array}{c}\text { Uncertainty } \\
\text { Processing } \\
\text { Method }\end{array}$} \\
\hline & Electric & Heat & PV & WT & Battery & CHPs & & & & \\
\hline $\begin{array}{c}\text { Haichao Wang } \\
\text { (2015) }\end{array}$ & $\sqrt{ }$ & $\sqrt{ }$ & $\sqrt{ }$ & & $\sqrt{ }$ & $\sqrt{ }$ & & $\sqrt{ }$ & & \\
\hline $\begin{array}{l}\text { Changzheng } \\
\text { Shao (2016) }\end{array}$ & $\sqrt{ }$ & $\sqrt{ }$ & & $\sqrt{ }$ & & $\sqrt{ }$ & & & & \\
\hline Pouya & & & & & & & & & & scenario \\
\hline $\begin{array}{l}\text { Pourghasem } \\
\text { (2019) }\end{array}$ & $\sqrt{ }$ & $\sqrt{ }$ & & $\sqrt{ }$ & & $\sqrt{ }$ & & & $\sqrt{ }$ & $\begin{array}{c}\text { generation } \\
\text { process }\end{array}$ \\
\hline $\begin{array}{c}\text { Yan Zhang } \\
\text { (2019) }\end{array}$ & $\sqrt{ }$ & $\sqrt{ }$ & $\sqrt{ }$ & $\sqrt{ }$ & $\sqrt{ }$ & $\sqrt{ }$ & & $\sqrt{ }$ & & $\begin{array}{l}\text { scenario } \\
\text { reduction } \\
\text { technique }\end{array}$ \\
\hline $\begin{array}{c}\text { Farhad } \\
\text { Nazari-Heri } \\
(2019)\end{array}$ & $\sqrt{ }$ & $\sqrt{ }$ & $\sqrt{ }$ & $\sqrt{ }$ & $\sqrt{ }$ & $\sqrt{ }$ & & $\sqrt{ }$ & & $\begin{array}{l}\text { scenario } \\
\text { generation } \\
\text { process }\end{array}$ \\
\hline This paper & $\sqrt{ }$ & $\sqrt{ }$ & $\sqrt{ }$ & $\sqrt{ }$ & $\sqrt{ }$ & $\sqrt{ }$ & $\sqrt{ }$ & $\sqrt{ }$ & $\sqrt{ }$ & FCM-CCQ \\
\hline
\end{tabular}

To deal with the problem mentioned above, we propose an optimal scheduling method based on stochastic optimization against the uncertainty of renewable energy output and consider the economy, environment, as well as system flexibility aspects in this paper. In addition, the operation mode of the CHP microgrid system and the behavior of system operators in different situations are discussed, and operational strategies are designed, respectively based on the interests of system operators and the environment. In short, the main contributions of this paper are included as follows.

(1) Considering system operation cost, carbon dioxide emissions cost, as well as system flexibility in the objective function.

(2) Based on the fuzzy C-means (FCM) clustering method, the number of historical scenarios of wind power and solar energy output can be reasonably reduced to a fixed value. Then, a novel clustering evaluation method named CCQ is proposed to determine the number of best scenario categories, which can reduce the uncertainty of renewable energy output compared with previous literature methods.

(3) A new demand side management method called integrated energy demand response is employed. Compared with a single electrical or heat load demand response method, the flexibility of the CHP microgrid system is improved, and the system operation cost is reduced significantly.

(4) The operation mode of the CHP microgrid and the behavior of the system operator in different situations are discussed, and different operational strategies are put forward in the light of the interests of system operators and environmental benefits.

The rest of proposed paper is organized as follows: Section 2 mainly describes the structure of the CHP microgrid and its mathematical model. Section 3 presents the objective functions and constraints of the CHP microgrid, and the solution to the proposed model. Case studies and simulation results as well as the corresponding operational strategy are explained in Section 4 . Section 5 summarizes the main conclusions in this paper.

\section{CHP Microgrid Structure Description and Mathematical Modelling}

In this section, The CHP microgrid system is introduced, which contains CHP units, photovoltaic, wind turbine, and the integrated energy demand response, as well as mathematical model of units.

\subsection{CHP System Composition and Structure}

The structure of a CHP microgrid system in this paper is illustrated in Figure 1, which contains two energy flows (electrical energy flow and thermal energy flow). In order to describe the impact of battery, integrated energy demand response, and grid connection on the operation of the CHP 
microgrid, we considered a CHP microgrid that includes a micro gas turbine (GT), a wind turbine (WT) unit, a photovoltaic cell (PV), a battery (BT), a gas boiler (GB), and a waste heat boiler (HB), along with electricity and heating loads.

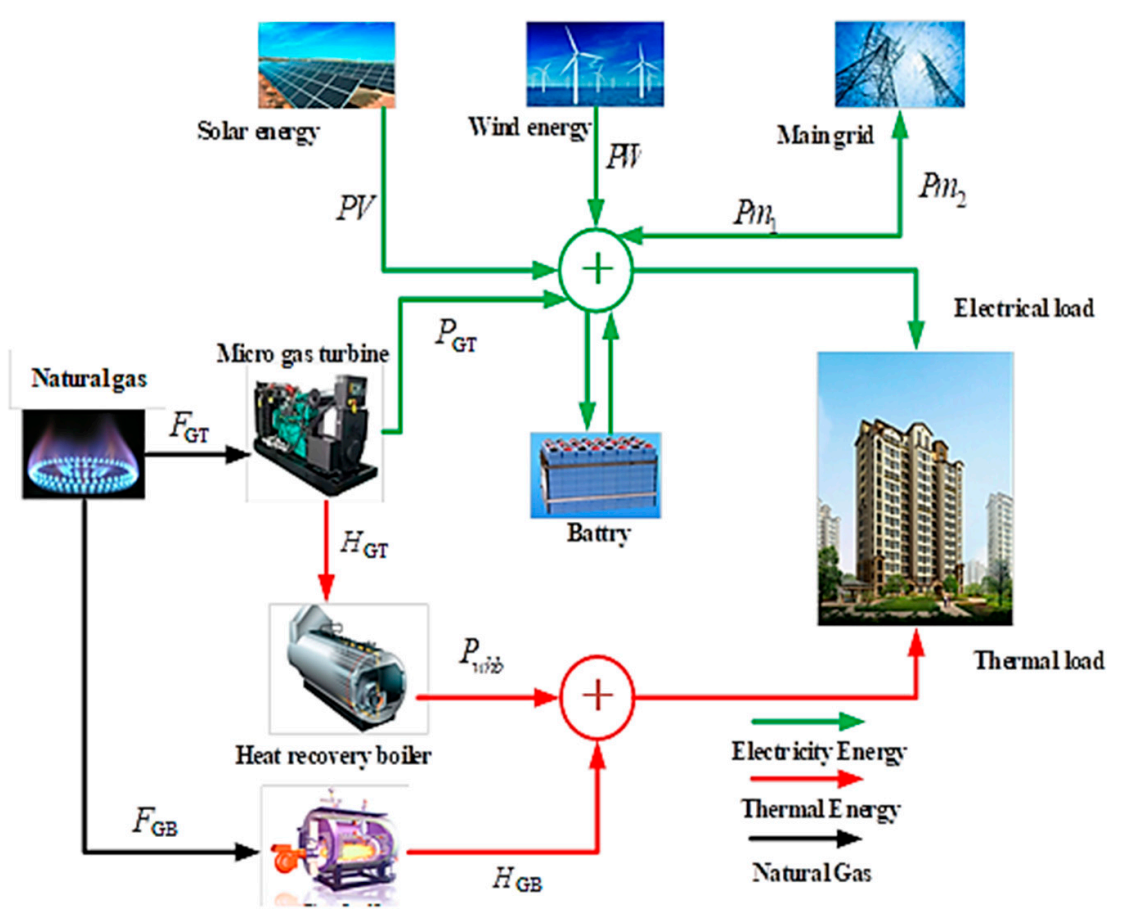

Figure 1. The structure of a combined heating and power $(\mathrm{CHP})$ microgrid system.

In this CHP microgrid system, PV and WT provide electricity to the microgrid with renewable solar and wind energy, respectively. GT and GB use natural gas as fuel to convert chemical energy into electricity and thermal energy into the microgrid. For the sake of achieving the cascade utilization of energy and improving energy efficiency, a HB is used to recover the waste heat generated by the GT. The BT performs real-time charging and discharging according to the operating state of the CHP microgrid system, which can ensure the balance of supply and demand of the electricity in the system and promote the maximum consumption of solar energy and wind energy. In addition, the CHP microgrid system can also exchange power with the main network. When the system cannot meet the user's electrical load demand, the system operator can purchase power from the main network to meet the user load, otherwise, the system operation can sell excess electricity to the main network for additional profit.

\subsection{Mathematical Modeling}

\subsubsection{Micro Gas Turbine}

The mathematical relationship between the energy output $P_{G T}^{t}$ and the natural gas consumption $F_{G T}^{t}$ can be modeled by the linear equation [25]:

$$
\begin{gathered}
F_{G T}^{t}=a P_{G T}^{t}+b U_{G T}^{t} \\
P_{G T}^{t}=P_{e t}^{t}+H_{G T}^{t}
\end{gathered}
$$

where $a$ and $b$ are gas-power conversion parameters. $U_{G T}^{t}$ represents the operating state of the micro gas turbine in each dispatch cycle that is equal to 1 if the GT is on in period $\mathrm{t}$ and 0 otherwise. $P_{e t}^{t}, H_{G T}^{t}$ denotethe electrical energy and thermal energy generated by the gas turbine in interval $t$, respectively.

Generally, there is a nonlinear relationship between input variables and output variables, which brings great difficulties to the solution of the problem. In order to optimize the solution, the thermal 
and electrical efficiency of the GT can be expressed as piecewise linearization, as shown in Figure 2, which can be modeled as mixed integer linear programming (MILP) [25].

$$
\begin{gathered}
U_{G T}^{t}=\sum_{n=1}^{l_{G T}} Z_{G T}^{t n} \\
\sum_{j=n+1}^{l_{G T}} Z_{G T}^{t n} \leq \frac{D_{G T}^{t n}}{M_{G T}^{n+1}-M_{G T}^{n}} \leq \sum_{j=n}^{l_{G T}} Z_{G T}^{t n} \\
H_{G T}^{t}=U_{G T}^{t} N_{G T}^{1}+\sum_{n=1}^{l_{G T}} C_{G T}^{n} D_{G T}^{t n}
\end{gathered}
$$

where $H_{G T}^{t}$ is the heat produced by the GT. $N_{G T}^{n}$ is the coefficient of the thermal and electrical efficiency curve. $M_{G T}^{n}$ represents the block limit of the thermal and electrical efficiency curve. $C_{G T}^{n}$ represents the slope of block $\mathrm{n}$ of the thermal and electrical efficiency curve. $Z_{G T}^{t n}$ is the binary variable encoding the thermal and electrical efficiency curve of the GT. $l_{G T}$ is the index set of the piecewise linear thermal and electrical efficiency curve.

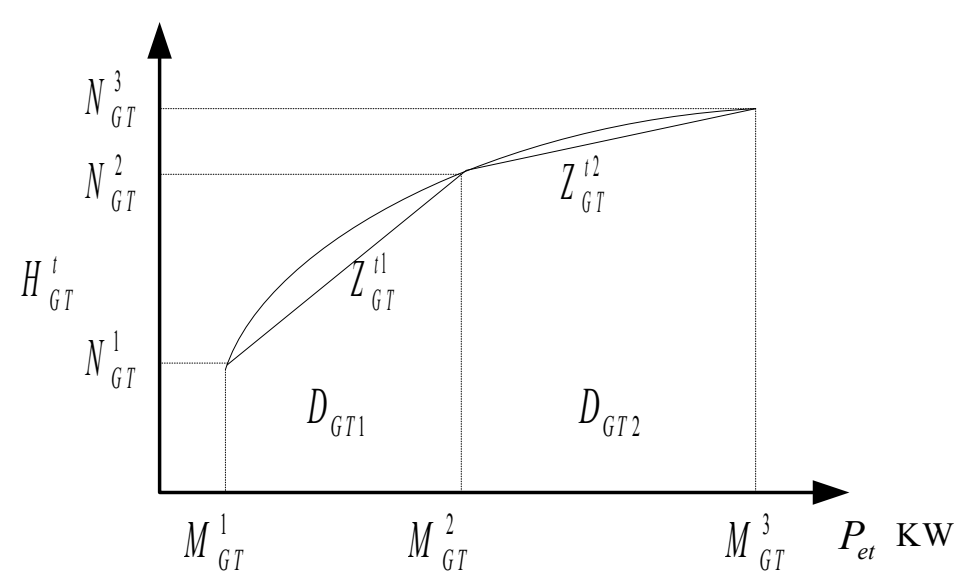

Figure 2. Piecewise linear approximation of thermal and electrical efficiency curve of the gas turbine (GT).

\subsubsection{Gas Boiler}

$$
\begin{gathered}
H_{G B}^{\min } \leq H_{G B}^{t} \leq H_{G B}^{\max } \\
F_{G B}^{t}=\frac{H_{G B}^{t}}{\eta_{G B} L H V}
\end{gathered}
$$

where $F_{G B}^{t}$ and $H_{G B}^{t}$ denote natural gas consumption and the power output of the gas boiler in interval $\mathrm{t}$, respectively. $\eta_{G B}$ denotes the efficiency of the gas boiler. $L H V$ is the low calorific value of natural gas.

2.2.3. Waste Heat Boiler

$$
\begin{gathered}
P_{w h b}^{t}=H_{G B}^{t} \eta_{w h b} \\
P_{w h h, \min } \leq P_{w h b}^{t} \leq P_{w h b, \max }
\end{gathered}
$$

where $P_{w h b}^{t}$ represents the heat recovered by the HB in period t. $\eta_{w h b}$ represents the recovery efficiency of the $\mathrm{HB}$, and $P_{w h b, \min }$ and $P_{w h b, \max }$ are the minimum and maximum power of the $\mathrm{HB}$, respectively. 
2.2.4. Exchange Power Between the Main Grid and the CHP Microgrid

$$
\left\{\begin{array}{l}
0 \leq P m_{1}{ }^{t} \leq U_{b u y}^{t} P m_{1}{ }^{\max } \\
0 \leq P m_{2}{ }^{t} \leq U_{\text {sell }}^{t} P m_{2}{ }^{\max } \\
U_{b u y}^{t}+U_{\text {sell }}^{t} \leq 1
\end{array}\right.
$$

where $P m_{1}{ }^{t}$ and $P m_{2}{ }^{t}$ represent electricity bought and sold to the main network in interval $t$, respectively. $U_{b u y}^{t}$ and $U_{\text {sell }}^{t}$ are the state of buying/selling, respectively, from/to main network in interval t.

\subsubsection{Battery}

$$
\left\{\begin{array}{l}
P D_{\min } U_{d i s s}^{t} \leq P D^{t} \leq P D_{\max } U_{d i s s}^{t} \\
P C_{\min } U_{c h a}^{t} \leq P C^{t} \leq P C_{\max } U_{c h a}^{t} \\
U_{d i s s}^{t}+U_{c h a}^{t} \leq 1 \\
S_{e s}^{t}=S_{e s}^{t}\left(1-\delta_{e s}\right)+\left(\xi_{e s}^{c h r} P C^{t}-P D^{t} / \xi_{e s}^{d i s s}\right) \Delta t \\
S O C_{\min } S_{e s} \leq S_{e s}^{t} \leq S O C_{\max } S_{e s}
\end{array}\right.
$$

where $P C^{t}$ and $P D^{t}$ denote charge/discharge power of battery in interval t, respectively. $U_{c h a}^{t}$ and $U_{\text {diss }}^{t}$ represent the charge/discharge state of the battery in interval $t$, where if battery is charging $\left(U_{c h a}^{t}=1\right)$ or discharging $\left(U_{\text {diss }}^{t}=1\right) . \delta_{e s}, \xi_{e s}^{c h r}$, and $\xi_{e s}^{\text {diss }}$ refer to the energy loss rate and charge/discharge efficiency of the battery, respectively. $S O C_{\min }$ and $S O C_{\max }$ refer to the lower, upper limits of state-of-charge. $S_{e s}$ is the rated capacity of the battery. $S_{e s}^{t}$ is the amount of battery stored in interval t.

\subsubsection{Integrated Energy Demand Response Program}

This paper introduces a new concept named integrated energy demand response (IEDR) to help the CHP microgrid system to reduce operating cost and increase system flexibility by changing the user's energy consumption pattern. In other words, the system operator can shift the load from peak time intervals to off-peak ones, as shown in Figure 3, to minimize the operating cost of the CHP microsystem as well as maximize the profit [14].

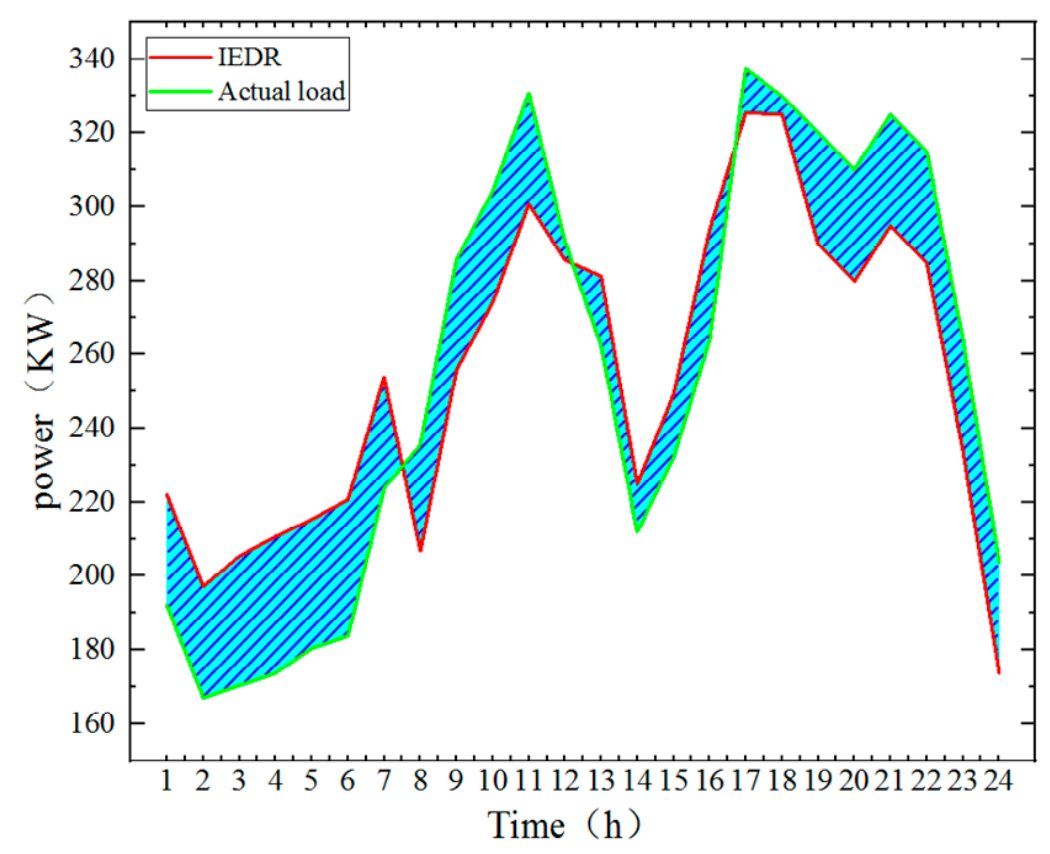

Figure 3. Comparison of energy load after implementing integrated energy demand response. 
2.2.7. Electric Energy

$$
\begin{aligned}
& E L o a d_{t}^{D R^{T L 1}}=\text { ELoad }_{t}+D R_{t}^{T L 1} \\
& -D R P_{\max 1} \times \text { ELoad }_{t} \leq D R_{t}^{T L 1} \leq D R P_{\max 1} \times \text { ELoad }_{t} \\
& \sum_{t=0}^{N} D R_{t}^{T L 1}=0(N=0,2,3, \ldots, 23)
\end{aligned}
$$

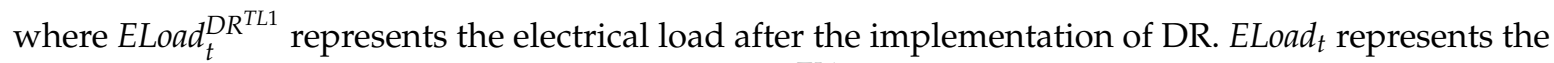
actual electrical load without implementing DR. $D R_{t}^{T L 1}$ indicates increased/decreased electrical load in DR. $D R P_{\max 1}$ indicates the maximum limitation of the consumer's participation in DR.

2.2.8. Thermal Energy

$$
\begin{aligned}
& \text { HLoad }_{t}^{D R^{T L 2}}=\text { HLoad }_{t}+D R_{t}^{T L 2} \\
& -D R P_{\max 2} \times \text { Hoad }_{t} \leq D R_{t}^{T L 2} \leq D R P_{\max 2} \times \text { HLoad }_{t} \\
& \sum_{t=0}^{N} D R_{t}^{T L 2}=0(N=0,2,3, \ldots, 23)
\end{aligned}
$$

where $H_{L o a d}{ }_{t}^{R L 2}$ is the thermal load after the implementation of DR. HLoad $t$ is the actual thermal load without implementing DR. $D R_{t}^{T L 2}$ represents increased/decreased thermal load in DR. $D R P_{\max 2}$ represents the maximum limitation of the consumer's participation in DR.

\section{CHP Microgrid Optimization Scheduling Strategy}

Stochastic programming is a method for dealing with uncertain decision problems and has been widely used in the field of power systems. This paper takes the output power of CHP units and the renewable energy as the decision variables, via converting stochastic programming to mixed linear programming (MILP) and solving it with MATLAB R2016b (MathWorks company, Natick, MA, USA, 2016) and CPLEX Optimization Studio v12.8(IBM company, Amund, New York, NY, USA, 2017).

\subsection{Objective Function}

The operation cost of the CHP microgrid system, which contains the power exchange cost with the main network, the maintenance cost of each unit, the $\mathrm{CO}_{2}$ emission cost, and natural gas procurement cost, should be minimized. The mathematical model of the objective function is shown below (14):

$$
f=\min \left(C_{e x c}+C_{g a s}+C_{m g t}+C_{m p v}+C_{m w t}+C_{m g b}+C_{m h b}+C_{m e s}+C_{c o_{2}}+C_{D R}\right)
$$

where $C_{\text {exc }}$ is the exchange power cost. $C_{g a s s}$ is the natural gas consumption cost. $C_{m g t}$ is the gas turbine maintenance cost. $C_{m p v}, C_{m w p}, C_{m g b}, C_{m h b}$, and $C_{m e s}$ represent the maintenance cost of each generating unit, respectively. $C_{\mathrm{CO}_{2}}$ is the $\mathrm{CO}_{2}$ emissions cost. $C_{D R}$ is the IEDR compensation cost.

3.1.1. The Cost of Exchange Power between the Main Network and the CHP Microgrid

$$
\left\{\begin{array}{l}
C_{b u y}=p_{b u y}^{t} P m_{1}^{t} \\
C_{\text {sell }}=p_{\text {sell }}^{t} P m_{2}^{t} \\
C_{\text {exc }}=C_{\text {buy }}-C_{\text {sell }}
\end{array}\right.
$$

where $C_{b u y}$ and $C_{\text {sell }}$ are electricity procurement/sales costs from or to the main network. $p_{b u y}^{t}$ and $p_{\text {sell }}^{t}$ are electricity procurement price and electricity sales price, respectively. 


\subsubsection{Natural Gas Consumption Cost}

$$
C_{g a s}=p_{g a s}\left(F_{G B}^{t}+F_{G T}^{t}\right)
$$

where $p_{g a s}$ represents natural gas price. $F_{G T}^{t}$ and $F_{G B}^{t}$ represent the amount of natural gas consumed by gas turbines and gas boilers in interval t.

\subsubsection{The Maintenance Cost of Each Unit}

$$
\left\{\begin{array}{l}
C_{m g t}=R_{m g t} P_{G T}^{t} \Delta t \\
C_{m g b}=R_{m g b} H_{G B}^{t} \Delta t \\
C_{m h b}=R_{m h b} P_{m h b}^{t} \Delta t \\
C_{m e s}=R_{m e s}\left(P D^{t}+P C^{t}\right) \Delta t \\
C_{m p v}=R_{m p v} P V^{t} \Delta t \\
C_{m w t}=R_{m w t} P W^{t} \Delta t
\end{array}\right.
$$

where $R_{m g t}, R_{m g b}, R_{m h b}, R_{m e s}, R_{m p v}$, and $R_{m w t}$ indicate the unit power maintenance cost of each unit in the CHP microgrid in interval $t$, respectively.

\subsubsection{Carbon Dioxide Emission Cost}

$$
C_{\mathrm{CO}_{2}}=P_{\mathrm{CO}_{2}}\left[C_{g t}\left(P_{G T}^{t}+H_{G T}^{t}\right)+C_{g b} H_{G B}^{t}+C_{g r i d} P m_{1}^{t}\right] \Delta t
$$

where $P_{\mathrm{CO}_{2}}$ represents carbon tax. $C_{g t}, C_{g b}$, and $C_{g r i d}$ indicate carbon dioxide emissions per unit of power from the GT, GB, and main network.

\subsubsection{Integrated Energy Demand Response Compensation Cost}

$$
C_{D R}=P_{E} \times D R_{t}^{T L 1}+P_{H} \times D R_{t}^{T L 2}
$$

where $P_{E}$ and $P_{H}$ represent the compensation price of the unit electric load/thermal load in the demand response program.

\subsection{CHP Microgrid System Constraints}

This section mainly describes the CHP microgrid system constraints, including the balance of electrical energy and thermal energy, as well as the technical constraints of the units.

- Electrical energy balance constraint

$$
P V^{t}+P W^{t}+P_{G T}^{t}+P D^{t}-P C^{t}+P m_{1}^{t}-P m_{2}^{t}=E_{L o a d}+D R_{t}^{T L 1}
$$

- Thermal energy balance constraint

$$
H_{G T}^{t}+H_{G B}^{t}=\text { Hload }_{t}+D R_{t}^{T L 2}
$$

- The technical constraints of the units.

The technical constraints of the units are described in Section 2.2 in detail. Please see Equations (1)-(11) for specific constraints.

\subsection{RESs Uncertainty Sets}

Since WT and PV power generation are subject to meteorological conditions, their power output has certain intermittency and volatility. In order to characterize the WT and PV, this paper adopted the 
improved fuzzy C-means (FCM) to cluster the historical power scenarios of wind power and solar energy out into several typical scenarios and then used the clustering comprehensive quality (CCQ) method to evaluate whether these scenarios are representative and determine the optimal number of scenarios [26].

\subsubsection{FCM Clustering Method}

In this paper, the objective function was established with all the same scenarios as the minimum total distance from the cluster center:

$$
\left\{\begin{array}{l}
f(u, v, w)=\operatorname{mim}\left(\sum_{j=1}^{n} \sum_{k=1}^{c} u_{k j}^{2} d_{k j}^{2}\right) \\
d_{k j}=\sqrt{\sum_{i=1}^{m}\left[w_{i}\left|a_{i j}-v_{i k}\right|\right]^{2}}
\end{array}\right.
$$

where $n$ represents the total number of scenarios; $c$ is the number of clusters, $u_{k j}$ is the relative membership of the sample $j$ to the category $k$; and $\sum_{k=1}^{c} u_{k j}=1,0 \leq u_{k j}<1, \sum_{j=1}^{n} u_{k j}>0 ; d_{k j}$ is the Euclidean distance between sample $j$ and category $k ; w_{i}$ is the weight of the $i$-th indicator, and $\sum_{i=1}^{m} w_{i}=1,0 \leq w_{i} \leq 1 ; v_{i k}$ is the clustering feature normalization number of the category $k$ indicator feature value $i, 0 \leq v_{i k} \leq 1$.

Usually, there are differences in the dimension and magnitude of each indicator in the system, so each indicator needs to be normalized, then $d_{k j}$ is updated to:

$$
d_{k j}=\sqrt{\sum_{i=1}^{m}\left[\frac{1}{m}\left|\frac{a_{i j}-a_{i j}^{\min }}{a_{i j}^{\max }-a_{i j}^{\min }}-v_{i k}\right|\right]^{2}}
$$

where $a_{i j}^{\max }$ and $a_{i j}^{\min }$ are the maximum and minimum values of the $i$-th indicator eigenvalues in the scenario sets, respectively.

Finally, via constructing the Lagrange function, the cluster iteration can be obtained, and the loop iteration can realize the scenario clustering.

$$
\begin{gathered}
u_{k j}=\frac{1}{\sum_{l=1}^{c}\left[\frac{\left.\sum_{i=1}^{m}\left(\frac{a_{i j} a_{i j}^{\min }}{a_{i j}^{\max }-a_{i j}^{\min }}-v_{i k}\right)^{2}\right]}{\left.\sum_{i=1}^{m}\left(\frac{a_{i j}-a_{i j}^{\min }}{a_{i j}^{\max }-a_{i j}^{\min }}-v_{i l}\right)^{2}\right]}\right.} \\
v_{i k}=\frac{\sum_{j=1}^{n} u_{k j}^{2} \frac{a_{i j}-a_{i j}^{\min }}{a_{i j}^{\max }-a_{i j}^{\min }}}{\sum_{j=1}^{n} u_{k j}^{2}}
\end{gathered}
$$

\subsubsection{CCQ Evaluation Method}

The appropriate number of clustering scenario categories can accurately reflect the characteristics of wind power and photovoltaic output and has a significant impact on the solution effect of the model. Thus, we adopted the CCQ method to determine the best scenario category.

The clustering effect can be expressed by the variance within the cluster. The larger the variance, the worse the clustering effect, and the smaller the variance, the better the clustering effect. 


$$
\operatorname{var}(X)=\sqrt{\frac{1}{n} \sum_{j=1}^{n}\left(x_{j}-\bar{x}\right)^{2}}
$$

where $n$ is the total number of scenes of set $X ; \bar{x}$ is the sample mean value corresponding to the eigenvalue of an index; and $x_{j}$ is the value of this indicator in the $j$-th scenario.

The distance between members within each cluster should theoretically be as close as possible, so the smaller the cluster density, the better.

$$
d_{e n}=\frac{1}{C} \sum_{j=1}^{C}\left[\frac{\operatorname{var}\left(c_{j}\right)}{\operatorname{var}(X)}\right]
$$

where $C$ is the sum scenarios after clustering; $\operatorname{var}\left(c_{j}\right)$ represents the variance in category $C_{j}$.

The clustering proximity and the distance between clusters are inversely proportional. The smaller the clustering proximity, the more effectively each cluster can be separated, indicating that the classification effect is better.

$$
p_{r o}=\frac{1}{C(C-1)} \sum_{j=1}^{C} \sum_{k=1, k \neq j}^{C} \exp \left[\frac{-\left(S_{C_{j}}-S_{C_{k}}\right)^{2}}{2 \delta^{2}}\right]
$$

where $S_{C_{j}}$ is the clustering center in category $C_{j} ; \delta$ is a gaussian constant and $2 \delta^{2}=1$ for simplified calculation.

In summary, this paper linearly combines clustering density and proximity, that is, the CCQ method, which can be expressed as:

$$
C_{o m}=1-\left[\xi D_{e n}+(1-\xi) p_{r o}\right]
$$

where $\xi \in[0,1]$ is the weight of equilibrium clustering density and clustering proximity, which is 0.5 in this paper. The average comprehensive quality evaluation of each index $\bar{C}_{o m}$ determines the optimal number of clustering, as shown in the following formula:

$$
\overline{\mathrm{C}}_{o m}=\frac{1}{m} \sum_{i=1}^{m} C_{o m}
$$

The solution procedure of the WT and PV scenario clustering and CHP microgrid optimization scheduling strategy is demonstrated in Figure 4. 

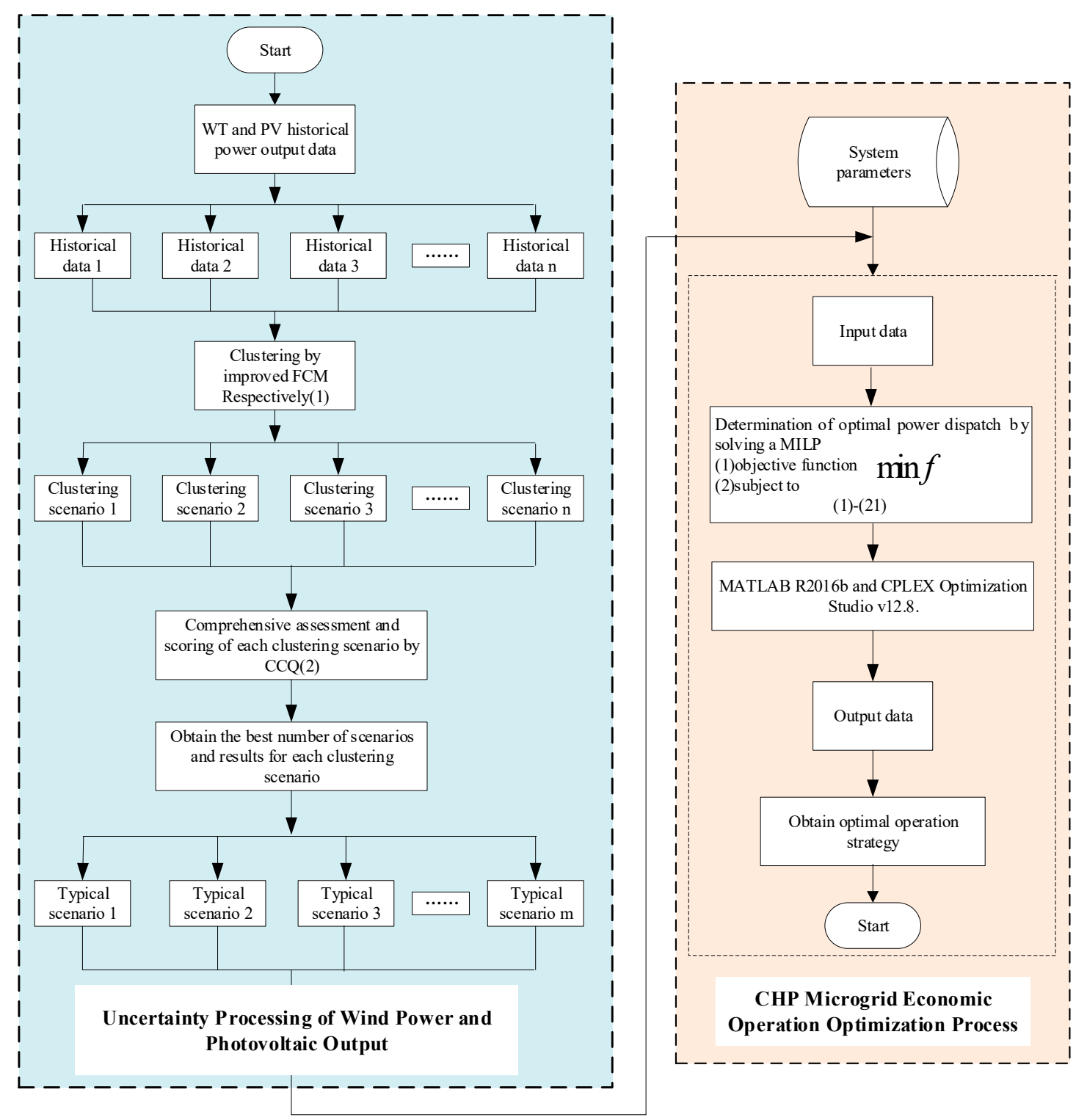

Figure 4. Stochastic optimization model solving process.

\section{Case Study}

In this section, the optimization scheduling strategy of CHP microgrid based on MILP is presented. This paper selected a residential area in Beijing China as the experimental system. The structure of the experimental system is illustrated in Figure 1.

\subsection{Data Analysis}

In this section, considering the time characteristics of WT and PV output and user load, as well as the fluctuation characteristics of electricity price, the optimal scheduling strategy of CHP microgrid system is presented. This paper selects the historical output power data of WT and PV in the winter in a residential area in Beijing, China, and 10 typical power output curves were obtained using the improved FCM and CCQ models, as shown in Figure 5a,b for PV and WT, respectively. The typical daily heat load curve and electric load curve are shown in Figure 6. The hourly price of electricity is observed in Figure 7. 


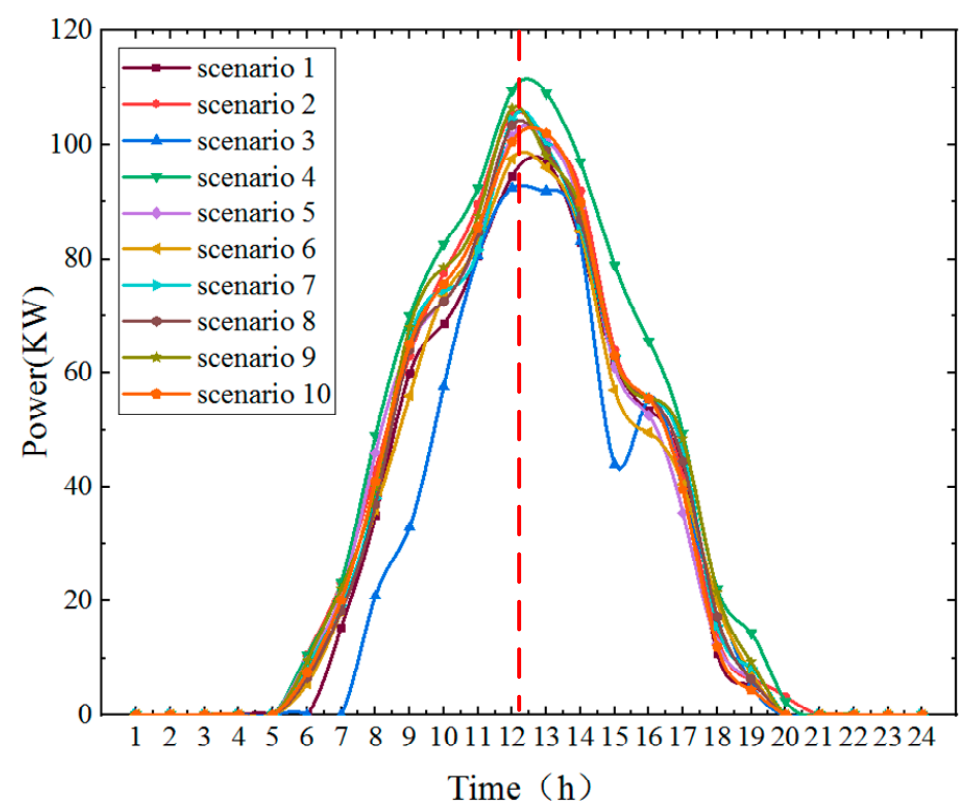

(a)

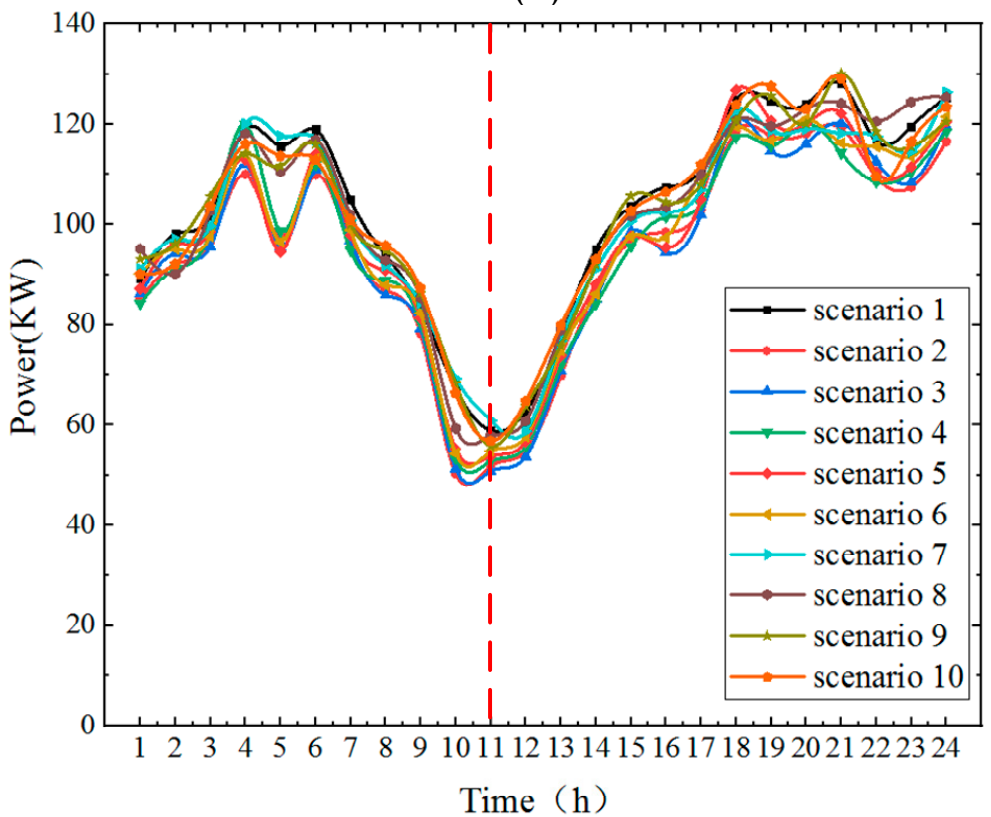

(b)

Figure 5. The power output curves of photovoltaic (PV) and wind turbine (WT): (a) PV unit output curve; (b) WT unit output curve.

According to Figure 5, the maximum power output period of the PV is 11:00-14:00. In this time period, the user's electricity load and thermal load gradually reduce and reach the minimum load at 14:00. The maximum output power of the WT ranges from 20:00 at night to 06:00 the next day. In this time period, the user's electrical load gradually reduces, and the thermal load begins to reduce after reaching the maximum load at 20:00. Obviously, PV is the perfect complement to WT. Further analysis indicates that the abandonment of wind and solar energy is more prone to take place under the low valley period of users' electricity load. In grid-connected mode, when the user's electricity load demand reaches the peak time, the renewable energy can be fully utilized, and the shortage of power is supplemented by the battery discharge or purchasing from the main grid; when the electricity load is in a low period, the extra power can be stored in the battery or sold to the main grid, which is beneficial to reduce the rejection rate of wind and solar energy. 
Figure 6 shows a typical user's 24-hour electricity and thermal load in winter. There are two peak periods of energy consumption and two valley periods. Figure 7 presents $24 \mathrm{~h}$ purchase and sale electricity prices of the main grid, which is divided into three sections: peak, flat, and valley.

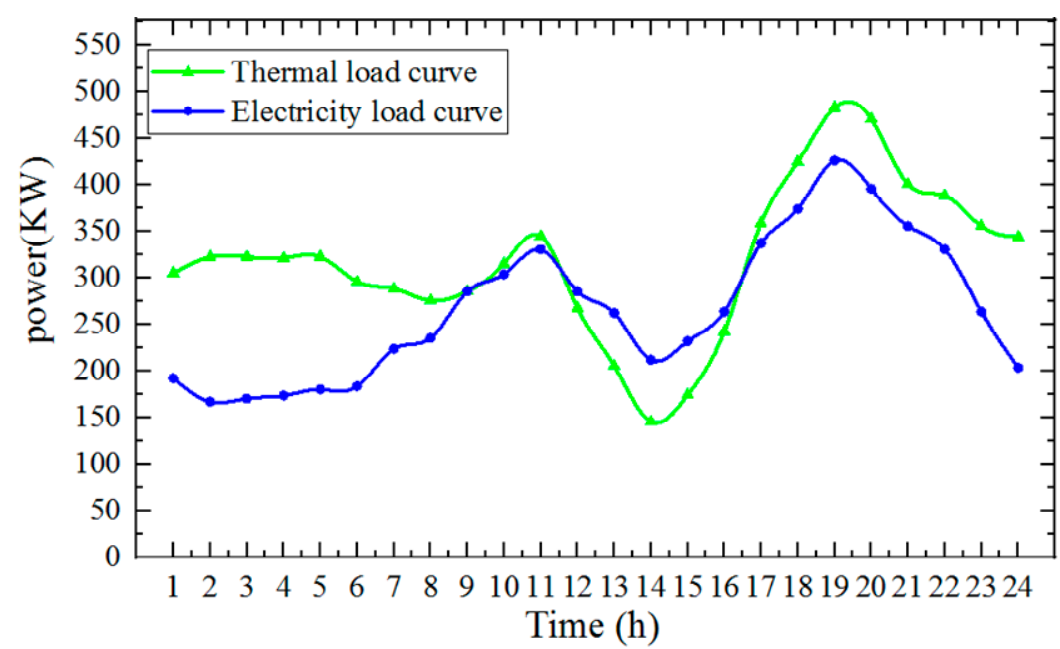

Figure 6. Electricity and Thermal load curves.

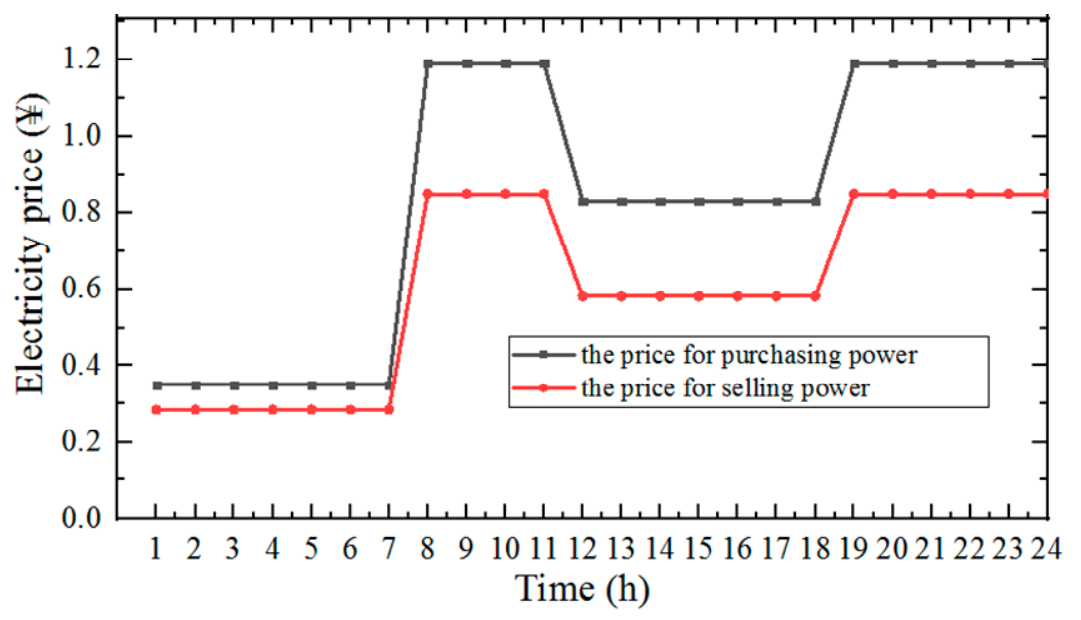

Figure 7. Hourly price of electricity curve.

Finally, the main parameters involved in the CHP microgrid system are shown in Table 2. The relevant parameters of carbon dioxide emissions are demonstrated in Table 3 [27].

Table 2. Technical parameters of the CHP microgrid.

\begin{tabular}{llll}
\hline Parameters & Value & Parameters & Value \\
\hline$\eta_{G T}$ & 0.8 & $p_{G T}^{\max }$ & $200 \mathrm{KWh}$ \\
$\eta_{w h b}$ & 0.85 & $p_{G T}^{\min }$ & $30 \mathrm{KWh}$ \\
$\eta_{G B}$ & 0.73 & $H_{G B}^{\max }$ & $500 \mathrm{KWh}$ \\
$\xi_{e s}^{c h r}, \xi_{e s}^{d i s s}$ & 0.95 & $p_{h b}^{\max }$ & $200 \mathrm{KWh}$ \\
$L H V$ & $9.7 \mathrm{KWh} / \mathrm{m}^{3}$ & $p_{p v}^{\max }$ & $100 \mathrm{KWh}$ \\
$R_{m p v}$ & $0.08 ¥ / \mathrm{KWh}$ & $p_{w t}^{\max }$ & $130 \mathrm{KWh}$ \\
$R_{m w t}$ & $0.11 ¥ / \mathrm{KWh}$ & $p m_{1}^{\max }$ & $200 \mathrm{KWh}$ \\
$R_{m e s}$ & $0.02 ¥ / \mathrm{KWh}$ & $p m_{2}^{\max }$ & $200 \mathrm{KWh}$ \\
$R_{m g t}$ & $0.01685 ¥ / \mathrm{KWh}$ & $P D_{\max }$ & $10 \mathrm{KWh}$ \\
$R_{m g b}$ & $0.02 ¥ / \mathrm{KWh}$ & $P C_{\max }$ & $5 \mathrm{KWh}$ \\
$R_{m h b}$ & $0.025 ¥ / \mathrm{KWh}$ & $S_{e s}$ & $20 \mathrm{KWh}$ \\
$D R P_{\max }$ & $30 \mathrm{KWh}$ & & \\
\hline
\end{tabular}


Table 3. Parameters of carbon emission.

\begin{tabular}{cccc}
\hline & Natural Gas & Electricity & Carbon Tax \\
\hline unit & $220(\mathrm{~g} / \mathrm{KWh})$ & $968(\mathrm{~g} / \mathrm{KWh})$ & $0.04345(\$ / \mathrm{kg})$ \\
\hline
\end{tabular}

\subsection{Analysis and Discussion of Results}

According to the actual operating characteristics of the CHP microgrid system, this paper analyzed the system operating cost, demand response compensation cost, and $\mathrm{CO}_{2}$ emission cost in five different operation modes based on various conditions affecting the economic operation of the CHP microgrid and then proposed corresponding strategies for system operators. The specific operation mode settings are shown in Table 4.

Table 4. Operation mode setting.

\begin{tabular}{ccccc}
\hline Operation Mode & IEDR & Battery & On-Grid & Islanded \\
\hline 1 & $\sqrt{ }$ & $\sqrt{ }$ & $\sqrt{ }$ & \\
2 & $\sqrt{ }$ & & $\sqrt{ }$ & \\
3 & & $\sqrt{ }$ & $\sqrt{ }$ & \\
4 & & & $\sqrt{ }$ & $\sqrt{ }$ \\
5 & $\sqrt{ }$ & $\sqrt{ }$ & & $\sqrt{ }$
\end{tabular}

By comparing the total cost of the five operation modes, integrated demand response compensation costs, and $\mathrm{CO}_{2}$ emission costs, the optimal economic dispatch strategy is obtained.

\subsubsection{Operation Mode 1}

In operation mode 1, the electricity load is provided by each microgenerator unit. As shown in Figure 8, only WT is working during the period from 01:00 to 07:00; at the same time, the price of electricity ( $0.35 ¥)$ is lower than the marginal cost $(0.605 ¥)$ of gas turbine power generation. In order to satisfy the users' load demand, the system operator needs to purchase electricity from the main grid and store a portion of it into the battery to cope with the future increase in electricity load. At 08:00-11:00, the PV unit and the gas turbine start to work, and as the power supply is greater than the demand, electricity price gradually increases; at this time, extra power is sold to the main grid for additional profits. At 12:00-18:00, the internal power supply of the CHP microgrid is balanced. At 19:00-22:00, it is at the peak hours of power consumption; only the power output of the WT and the GT in the system are insufficient to meet the user's electricity load, so in order to avoid purchasing a large amount of electricity from the main grid in the high price period and reduce system operating costs, the system operator needs IEDR to transfer users' load. During the period of 23:00-24:00, the electricity load drops sharply, and the surplus electricity in the system is sold to the main grid for profit. This method effectively improves the flexibility and power supply reliability of the CHP microgrid.

Figure 9 clearly illustrates the purchase and sale of electricity as well as charge and discharge behaviors of the CHP microgrid at various times. When the electricity price is low, the electricity is purchased; otherwise, the electricity is sold. In addition, the total amount of electricity sold is more than purchased, which indicates that in the grid-connected mode, the CHP microgrid can promote the consumption of renewable energy, and system operators can also obtain more revenue.

Figure 10 shows that the users' thermal load in the CHP microgrid system is always in balance. Changes in users' electricity demand will not affect thermal load, because this mode of operation achieves a partially decoupling heat production from electricity generation. Compared with the traditional "heat-set" and "electricity-set" modes of operation, this mode of CHP microgrid is more flexible and more efficient in energy utilization. Finally, the operation cost of the system is 6188.1433¥, and the cost of $\mathrm{CO}_{2}$ emission is 879.9429¥. 


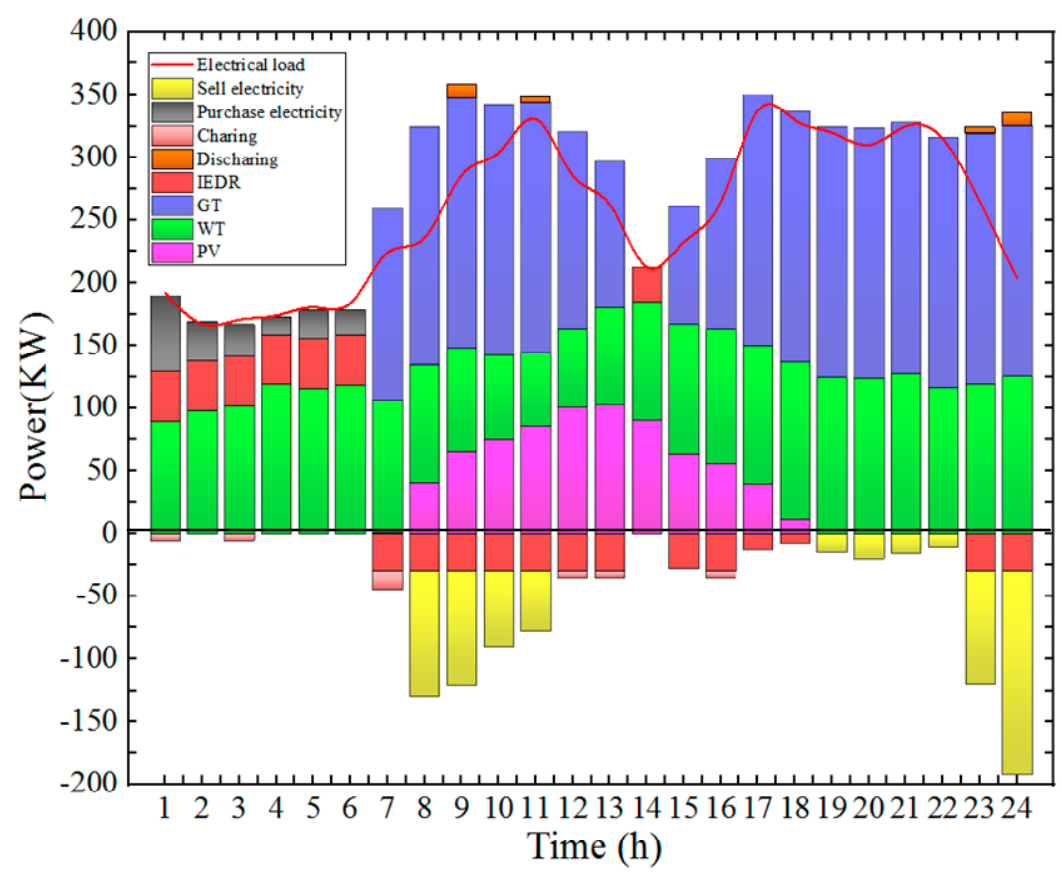

Figure 8. Real-time operating status of CHP microgrid system components.

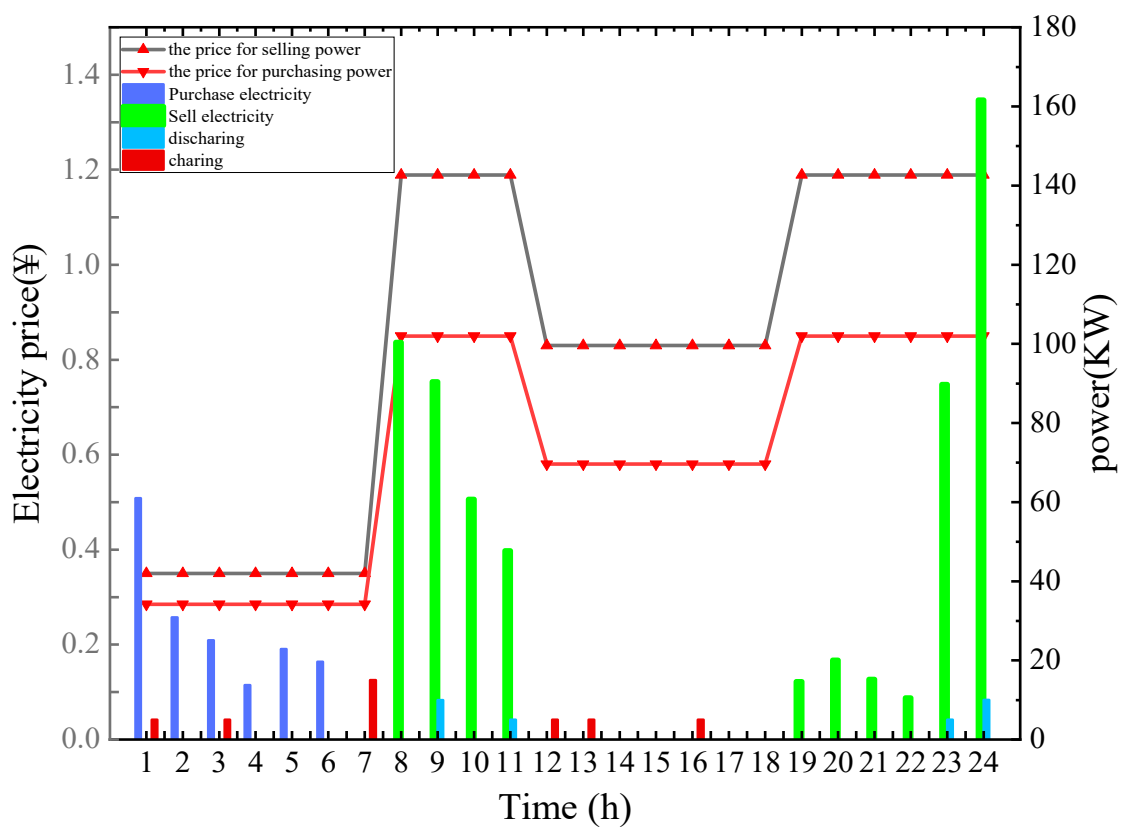

Figure 9. Real-time operating status of battery and interaction with the main network.

\subsubsection{Operation Mode 2}

In operation mode 2, there is no battery device in the system. In order to ensure the balance of electric power in the system, the system operator either sells extra power to the main grid or shuts down the PV and WT power output. In the power shortage period, the users' power demand cannot be satisfied after implementing the demand response; the system operator needs to purchase power from the main network, thereby causing an increase in operating cost. Further, the flexibility of the CHP microgrid is greatly reduced because of the absence of a battery device. When the grid is interrupted, the system fails to respond in time and will cause serious economic losses. The operation cost of the system calculated by simulation is 6191.6159¥, and the cost of $\mathrm{CO}_{2}$ emission is $875.2604 ¥$. 


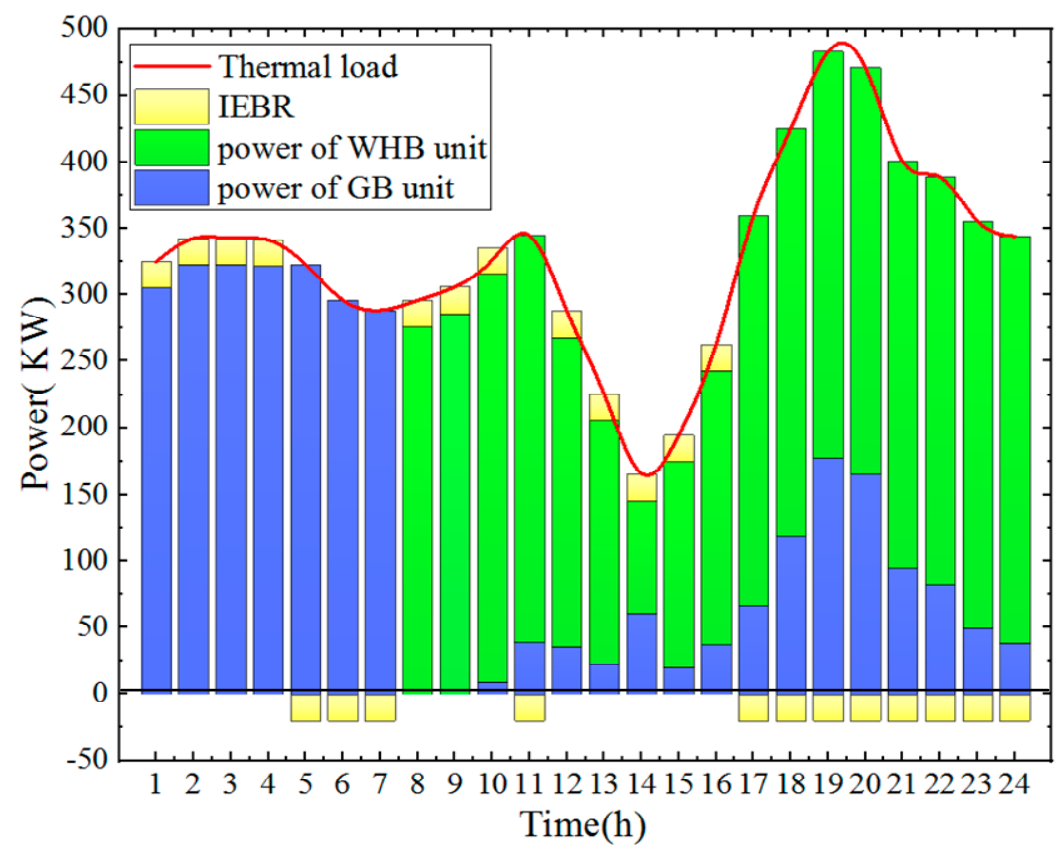

Figure 10. The scheduling output of heat generation components.

\subsubsection{Operation Mode 3}

IEDR is an effective solution for power demand side management that can intelligently control various energy loads within the system, increase system flexibility, and maximize energy resilience and savings on operating cost. Implementing demand response to adjust the demand side load, the user's electricity habits can be improved, and the maximum load of the microgrid grid as well as the installed capacity of the system can be reduced. In this mode of operation, the user cannot interact with the CHP microgrid system. In the peak load period, the system operator can only purchase power from the main grid to meet the user load and increase the system purchase cost. Due to the lack of timely response of users to the power grid, the operation security of the CHP microgrid system is not guaranteed, and the reliability of power supply is doubtful. Through modeling and calculation, the operation cost of the system is $6269.3646 ¥$, and the cost of $\mathrm{CO}_{2}$ emission is 849.3497¥.

\subsubsection{Operation Mode 4}

The battery and IEDR are considered as an auxiliary function that can improve system flexibility and energy efficiency. Without battery and IEDR, the cost of system operation is higher than that in operation modes 2 and 3 . The operation cost of the system calculated by simulation is $6272.7725 ¥$, and the cost of $\mathrm{CO}_{2}$ emission cost is 843.9117¥.

\subsubsection{Operation Mode 5}

Under the condition of isolated main grid operation, the internal electricity load of the CHP microgrid system is completely provided by PV, WT, and GT. When the power supply is insufficient, it will cause a large-scale power outage and bring inconvenience to people's daily lives. When the power is surplus, little power is generated by the PV and WT units and massive renewable energy is wasted, which is not conducive to sustainable development. The operation cost of the system calculated by simulation is 6372.2021¥, and the cost of $\mathrm{CO}_{2}$ emission is 697.7986

\subsubsection{Comparative Analysis of Results}

The economic operation of the CHP microgrid system is very complicated and is limited by external environmental interference and its own factors. The system operation mode will vary with 
changes in the combination of various factors. The results of the above five different $\mathrm{CHP}$ microgrid operation modes are shown in Table 5.

Table 5. Comparison of system operation costs in different cases under integrated energy demand response.

\begin{tabular}{|c|c|c|c|c|c|c|c|}
\hline \multirow{2}{*}{$\begin{array}{c}\text { Operation } \\
\text { Mode }\end{array}$} & \multicolumn{3}{|c|}{ System Structure } & \multirow{2}{*}{$\begin{array}{l}\text { System } \\
\text { Operation } \\
\text { Cost (¥) }\end{array}$} & \multirow{2}{*}{$\begin{array}{c}\text { IEDR } \\
\text { Compensation } \\
\text { Cost }(¥)\end{array}$} & \multirow{2}{*}{$\begin{array}{c}\mathrm{CO}_{2} \\
\text { Emission } \\
\text { Cost }(¥)\end{array}$} & \multirow{2}{*}{$\begin{array}{c}\text { Proportion of } \\
\text { Electricity } \\
\text { Purchase }\end{array}$} \\
\hline & On-Grid & DR & Battery & & & & \\
\hline 1 & $\sqrt{ }$ & $\sqrt{ }$ & $\sqrt{ }$ & 6188.1433 & 907.4090 & 879.9429 & $10.07 \%$ \\
\hline 2 & $\sqrt{ }$ & $\sqrt{ }$ & & 6191.6159 & 886.7599 & 875.2604 & $9.88 \%$ \\
\hline 3 & $\sqrt{ }$ & & $\sqrt{ }$ & 6269.3646 & 0 & 849.3497 & $9.46 \%$ \\
\hline 4 & $\sqrt{ }$ & & & 6272.7725 & 0 & 843.9117 & $9.19 \%$ \\
\hline 5 & & $\sqrt{ }$ & $\sqrt{ }$ & 6372.2021 & 797.4766 & 697.7986 & 0 \\
\hline
\end{tabular}

Table 5 presents the operation cost, the $\mathrm{CO}_{2}$ emission cost, integrated demand response compensation cost, and the proportion of electricity purchased from the main network in the above five operation modes. The comparison between operation modes 1 and 2 shows that adding a battery device to the $\mathrm{CHP}$ microgrid can reduce the total system cost, but the $\mathrm{CO}_{2}$ emission cost will increase, because the system operator will purchase electricity and store it in the battery at a low electricity price, then sell it at a peak electricity price for additional profit. As a medium for storing electricity, the battery makes it possible for the system operator to purchase more power from the main grid at a lower price, which leads to an increase in the cost of $\mathrm{CO}_{2}$ emissions. The behavior of earning a differential profit is completely in line with the idea of time-of-use price. In other words, this method is called the arbitrage behavior of the system operator. A comparison between operation modes 1 and 3 shows that the implementation of the integrated demand response program can also motivate operators' arbitrage behavior, which decreases the total system cost and has a greater impact on the operator than that of the battery device. A comparison between operation modes 1 and 5 shows that in the isolated model, the electricity exchange cannot be performed between the CHP microgrid and the main grid, and the internal electricity supply of the CHP microgrid is completely provided by the WT, PV, and GT. When the system load demand exceeds the system supply capacity, in order to maintain the safety of the power system, the system operator must perform load shedding, which may result in damage to the user's interests. When the power supply exceeds the demand, the system operator must reduce the output of the generator unit, which may lead to the abandonment of wind and solar energy.

Figure $11 \mathrm{a}, \mathrm{b}$ shows the relationship between the proportion of electricity purchase and system operation cost and $\mathrm{CO}_{2}$ emission cost, respectively. It could be clearly judged from the simulation results that there is a close relationship between factors. As the proportion of electricity purchases goes up, the $\mathrm{CO}_{2}$ emission also gradually increases, while the operating cost of the system gradually decreases and tends to stabilize. The more electricity you buy from the main grid, the more the $\mathrm{CO}_{2}$ emission. The relationship between these factors is very complicated, involving electricity prices, carbon taxes, etc.

Table 6 shows the changes in various costs in the CHP microgrid system under traditional demand response. Comparing operation mode 1 in Tables 3 and 4, it can be concluded that the implementation of the IEDR can effectively reduce the system operation cost and $\mathrm{CO}_{2}$ emission cost, and the proportion of power purchase is also reduced by about $3 \%$, but the cost of demand response compensation will increase. From operation mode 5, it can be concluded that in the isolated operation mode, the implementation of the IEDR does not change the operation mode of the system, and the system operation cost and $\mathrm{CO}_{2}$ emission cost will not decrease. By contrast, the demand response compensation cost is greatly reduced. Therefore, the system operator should select the appropriate demand response mode according to the operating state of the microgrid to minimize the system cost. 


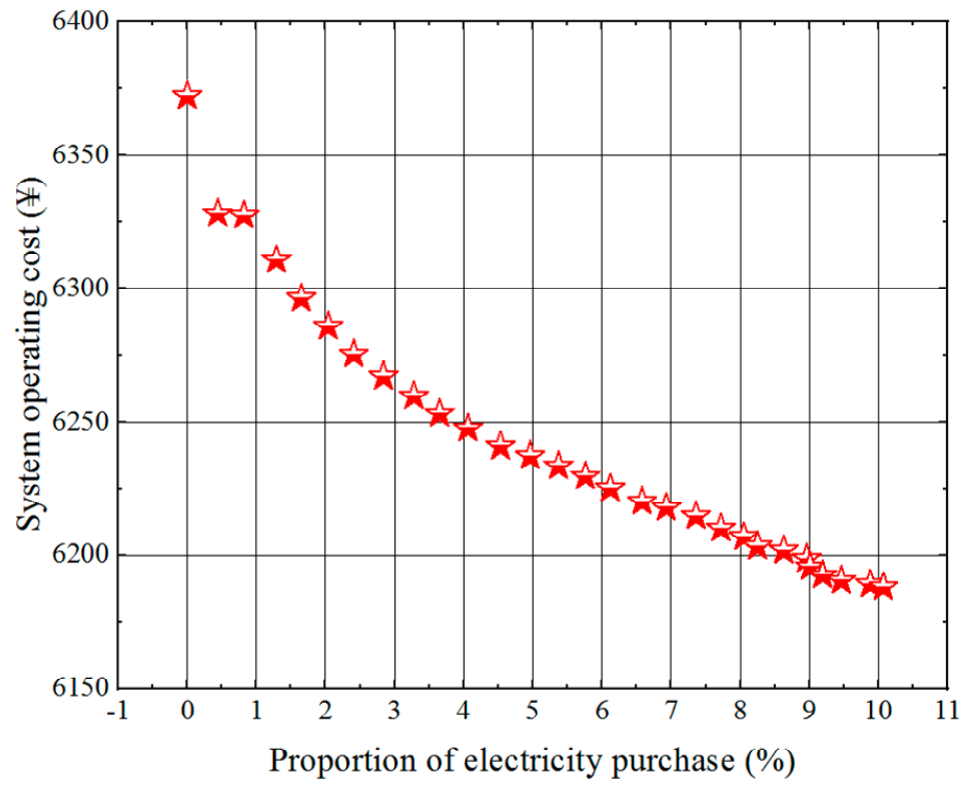

(a)

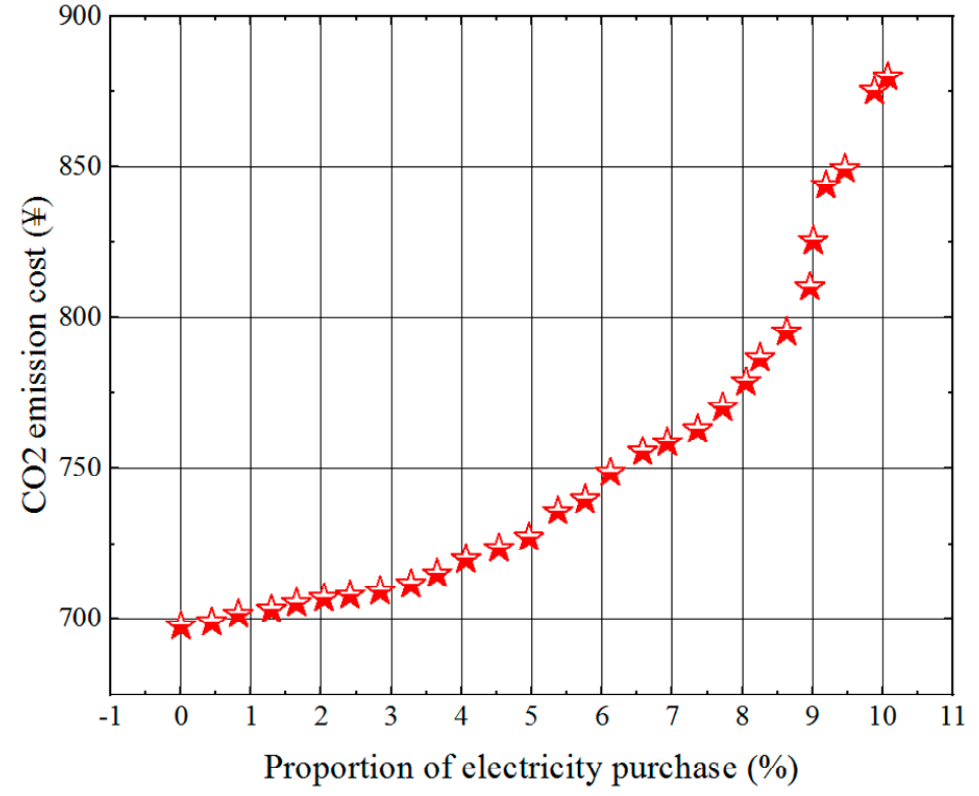

(b)

Figure 11. The relationship between the proportion of electricity purchase and cost. (a) The relationship between the proportion of electricity purchase and system operation; (b) The relationship between the proportion of electricity purchase and $\mathrm{CO}_{2}$ emission.

Table 6. Comparison of system operation costs in different operation modes without heat demand response.

\begin{tabular}{|c|c|c|c|c|c|c|c|}
\hline \multirow{2}{*}{$\begin{array}{l}\text { Operation } \\
\text { Mode }\end{array}$} & \multicolumn{3}{|c|}{ System Structure } & \multirow{2}{*}{$\begin{array}{l}\text { System } \\
\text { Operation } \\
\text { Cost (¥) }\end{array}$} & \multirow{2}{*}{$\begin{array}{c}\text { DR } \\
\begin{array}{c}\text { Compensation } \\
\text { Cost }(¥)\end{array}\end{array}$} & \multirow{2}{*}{$\begin{array}{c}\mathrm{CO}_{2} \\
\text { Emission } \\
\text { Cost }(¥)\end{array}$} & \multirow{2}{*}{$\begin{array}{c}\text { Proportion o } \\
\text { Electricity } \\
\text { Purchase }\end{array}$} \\
\hline & On-Grid & DR & Battery & & & & \\
\hline 1 & $\sqrt{ }$ & $\sqrt{ }$ & $\sqrt{ }$ & 6199.3748 & 521.4735 & 915.8112 & $13.01 \%$ \\
\hline 2 & $\sqrt{ }$ & $\sqrt{ }$ & & 6202.5363 & 521.4735 & 877.4196 & $10.25 \%$ \\
\hline 5 & & $\sqrt{ }$ & $\sqrt{ }$ & 6372.2021 & 427.4089 & 697.7986 & 0 \\
\hline
\end{tabular}




\subsubsection{Analysis of Economic Benefits of Microgrid by Energy Storage Unit}

$\mathrm{CHP}$ microgrid operation is affected by many factors, some of which are variable, such as battery capacity, and some factors which are immutable, such as demand response plan, carbon tax, which are formulated according to policies, and once determined, they will not change for a while. Therefore, this paper studied the impact of battery capacity changes on the economic benefits of the CHP microgrid and obtained the optimal battery capacity under the optimal economic operating condition, which provides a theoretical reference for social capital investment in wind power and the photovoltaic industry.

The energy in the energy storage system can flow in both directions, which can suppress the fluctuation of the load, cut the peak, and fill the valley in the power system, so the power system can maintain system balance at all times. Figure 12 shows that as the battery capacity changes, the operation cost of the CHP microgrid changes accordingly.

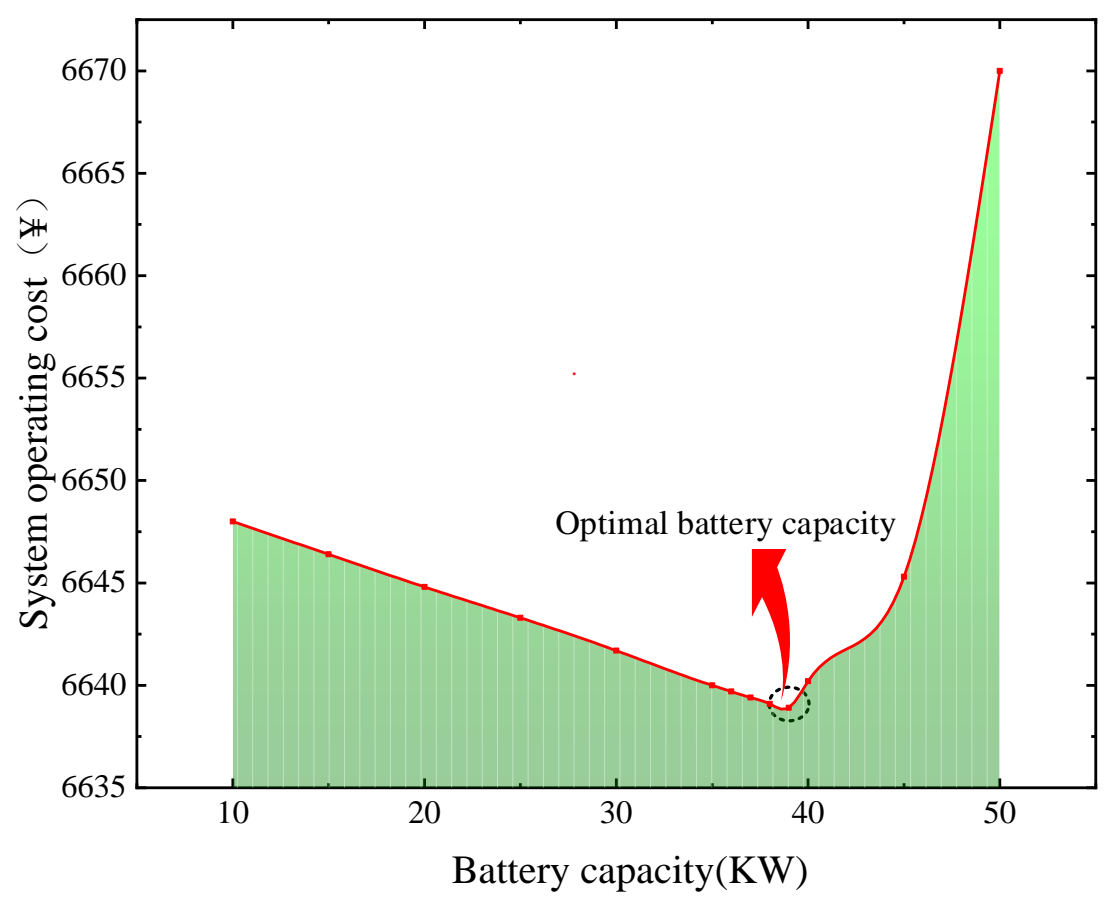

Figure 12. Relationship between battery capacity configuration and system operation cost.

It can be seen from Figure 12 that as the battery capacity increases, the system cost gradually decreases. When the battery capacity reaches $39 \mathrm{KW}$, the system cost is minimized, and then the system cost increases rapidly as the battery capacity increases. In the process of battery capacity change, when the battery capacity is less than $39 \mathrm{KW}$, as the battery capacity increases, the power exchange between the system operator and the main network is promoted, and the profit obtained by the operator is higher than the maintenance cost and installation cost of the battery; when the battery capacity is greater than $39 \mathrm{KW}$, although the power exchange between the system operator and the main network is promoted, the profit obtained by the operator is less than the maintenance cost and installation cost of the battery. Therefore, it is necessary to comprehensively measure the impact of battery capacity on the economic operation of the microgrid and ameliorate the economic benefits of the CHP microgrid in practice.

\subsection{Operational Strategy}

In this paper, we assumed that the CHP microgrid system is consistent with the interest of users and analyzed the operation mode of the CHP microgrid system from the perspective of the environment and the microgrid operator benefits, respectively. For a microgrid system operator, the ultimate goal is to minimize the system operating cost and maximize the profits, so operation mode 1 is the best 
strategy choice. When there is a battery and an IEDR is implemented under grid connection, the operator can minimize the system operating cost, because the operator can sell the electricity in peak time stored in the battery and shift the peak power consumption to the low valley period to avoid buying electricity from the main grid when electricity prices are high. Therefore, the total operating cost of operation mode 1 is lower than that of the other three operating modes, but since the $\mathrm{CO}_{2}$ emissions per $\mathrm{kWh}$ are much greater than the amount generated by the natural gas fuel from Table 1 , as a result, the $\mathrm{CO}_{2}$ emission cost of operation mode 1 is relatively high. From the perspective of environmental benefits, the $\mathrm{CO}_{2}$ emissions cost of operation mode 5 is the lowest, because under the condition of the isolated model, there is no way for the CHP microgrid system and the main grid to trade electricity with each other, the electricity load all satisfied by the internal generator units of the system. Furthermore, WT and PV will not produce any $\mathrm{CO}_{2}$ in the CHP microgrid system. GT uses natural gas as a fuel to generate energy, which also produces $\mathrm{CO}_{2}$; despite this, it produces much less $\mathrm{CO}_{2}$ than that of the main network. Therefore, operation mode 5 should be selected in consideration of environmental benefits. In summary, the economic operation strategy of the CHP microgrid is a complex project, an excellent operation strategy balancing interests and environment, which not only minimizes the operating cost but also considers various factors within the system (e.g., unit power limit, maintenance plan) and external environment (e.g., weather conditions, government policies, operator behavior).

\section{Conclusion}

This paper mainly studied the operation mode of the CHP microgrid system with RESs and the behavior of system operators in different scenarios to improve the efficiency of RES use and proposes the operating strategy for system operators under the power market. Considering the battery and IEDR, a MILP model was utilized to optimize the CHP microgrid with RESs. Firstly, considering the uncertainty and volatility of WT and PV output, the FCM and CCQ clustering evaluation method were used to cluster the WT and PV historical power output data into the optimal scenario number, and then the clustering results were comprehensively evaluated to obtain the best typical scenario. Secondly, the MILP method was used to simulate the optimized scheduling of the CHP microgrid in different scenarios, and the operating status of each unit, total system cost, $\mathrm{CO}_{2}$ emission cost, and integrated demand response compensation cost in the system were obtained. Finally, the behavior of the system operator in different scenarios was analyzed. The results indicate that the battery and IEDR can increase system flexibility and reduce system operating cost. In the grid-connected mode, a shrewd system operator can profit handsomely by making an optimal operation strategy and trading electricity at the time-of-use price. In this regard, more social capital will be introduced to invest in the development of RESs in the future, which is conducive to environmental improvement and sustainable social development. Compared with previous works, the main research in this paper was as follows: (1) an economic operation strategy of the CHP microgrid with RESs considering $\mathrm{CO}_{2}$ emission, battery, and IEDR was conducted; (2) a novel scene clustering method (FCM-CCQ) was adopted, which can not only cluster but also evaluate whether the scene clustering number is the optimal result; and (3) considering the uncertainty of renewable energy output.

Additionally, we proposed five different operating modes for the CHP microgrid and obtained the results by simulation. After analyzing the results, the strategy choices of the system operators under different circumstances were presented.

Finally, there are some shortcomings in this paper, which are that we did not consider the start-stop cost of generator units, the climbing slope constraint, and the model being idealized. However, it is hoped that the work can provide a useful reference for CHP microgrid economic optimization scheduling containing RESs. In future research, the influence of various factors will be comprehensively considered, making the model construction closer to the actual situation.

This paper can provide useful reference for CHP microgrid economic optimization scheduling containing RESs. As a future work, the influence of various factors will be given more comprehensive 
consideration, making the model construction more dynamic and accurate. Further, the start-stop cost of generator units and the climbing slope constraint can be employed in this model.

Author Contributions: J.D. and H.H. supervised the proposed research work, whereas S.N. conceptualized the proposed research work, collected the data, programmed and analyzed the methodology, and wrote the original draft. P.Y., A.F and J.L. helped in review writing and editing with validation of research work.

Funding: This research was funded by the Beijing social science foundation research base project (18JDGLB037).

Conflicts of Interest: The authors declare no conflict of interest.

\section{References}

1. Eurostat. Share of Renewable Energy Up to 14.1\% of Energy Consumption in the EU28 in 2012; Eurostat: Brussels, Belgium, 11 March 2014.

2. The 13th Five-Year Plan for Renewable Energy Development in China; National Development and Reform Commission: Beijing, China, December 2016.

3. Majidi, M.; Mohammadi-Ivatloo, B.; Anvari-Moghaddam, A. Optimal robust operation of combined heat and power systems with demand response programs. Appl. Therm. Eng. 2019, 149, 1359-1369. [CrossRef]

4. Zhu, C.; Xu, B.; Nie, Y.Z. An Integrated Design and Operation Optimal Method for CCHP System. Energy Procedia 2019, 158, 1360-1365. [CrossRef]

5. Pashaei-Didani, H.; Nojavan, S.; Nourollahi, R.; Zare, K. Optimal economic-emission performance of fuel cell/CHP/storage based microgrid. Int. J. Hydrog. Energy 2019, 44, 6896-6908. [CrossRef]

6. Izadbakhsh, M.; Gandomkar, M.; Rezvani, A.; Ahmadi, A. Short-term resource scheduling of a renewable energy based micro grid. Renew. Energy 2015, 75, 598-606. [CrossRef]

7. Shao, C.; Li, C.; You, X.; Wu, H.; Zhang, J.; Ding, Y.; Song, Y. Optimal coordination of CHP plants with renewable energy generation considering substitutability between electricity and heat. Energy Procedia 2016, 103, 100-105. [CrossRef]

8. Wang, H.; Yin, W.; Abdollahi, E.; Lahdelma, R.; Jiao, W. Modelling and optimization of CHP based district heating system with renewable energy production and energy storage. Appl. Energy 2015, 159, 401-421. [CrossRef]

9. Pourghasem, P.; Sohrabi, F.; Abapour, M.; Mohammadi-Ivatloo, B. Stochastic multi-objective dynamic dispatch of renewable and CHP-based islanded microgrids. Electr. Power Syst. Res. 2019, 173, 193-201. [CrossRef]

10. Moghaddam, A.A.; Seifi, A.; Niknam, T.; Pahlavani, M.R.A. Multi-objective operation management of a renewable MG (micro-grid) with back-up micro-turbine/fuel cell/battery hybrid power source. Energy 2011, 36, 6490-6507. [CrossRef]

11. Niknam, T.; Azizipanah-Abarghooee, R.; Roosta, A.; Amiri, B. A new multi-objective reserve constrained combined heat and power dynamic economic emission dispatch. Energy 2012, 42, 530-545. [CrossRef]

12. Ren, H.; Wu, Q.; Gao, W.; Zhou, W. Optimal operation of a grid-connected hybrid PV/fuel cell/battery energy system for residential applications. Energy 2016, 113, 702-712. [CrossRef]

13. Maleki, A.; Hafeznia, H.; Rosen, M.A.; Pourfayaz, F. Optimization of a grid-connected hybrid solar-wind-hydrogen CHP system for residential applications by efficient metaheuristic approaches. Appl. Therm. Eng. 2017, 123, 1263-1277. [CrossRef]

14. Alipour, M.; Zare, K.; Mohammadi-Ivatloo, B. Short-term scheduling of combined heat and power generation units in the presence of demand response programs. Energy 2014, 71, 289-301. [CrossRef]

15. Firouzmakan, P.; Hooshmand, R.A.; Bornapour, M.; Khodabakhshian, A. A comprehensive stochastic energy management system of micro-CHP units, renewable energy sources and storage systems in microgrids considering demand response programs. Renew. Sustain. Energy Rev. 2019, 108, 355-368. [CrossRef]

16. Aghaei, J.; Alizadeh, M.I. Multi-objective self-scheduling of CHP (combined heat and power)-based microgrids considering demand response programs and ESSs (energy storage systems). Energy 2013, 55, 1044-1054. [CrossRef]

17. Alipour, M.; Zare, K.; Seyedi, H.; Jalali, M. Real-time price-based demand response model for combined heat and power systems. Energy 2019, 168, 1119-1127. [CrossRef] 
18. Hosseinnia, H.; Tousi, B. Optimal operation of DG-based micro grid (MG) by considering demand response program (DRP). Electr. Power Syst. Res. 2019, 167, 252-260. [CrossRef]

19. Wu, J.; Zhang, B.; Jiang, Y.; Bie, P.; Li, H. Chance-constrained stochastic congestion management of power systems considering uncertainty of wind power and demand side response. Int. J. Electr. Power Energy Syst. 2019, 107, 703-714. [CrossRef]

20. Korprasertsak, N.; Leephakpreeda, T. Robust short-term prediction of wind power generation under uncertainty via statistical interpretation of multiple forecasting models. Energy 2019, 180, 387-397. [CrossRef]

21. Shukla, A.; Singh, S.N. Clustering based unit commitment with wind power uncertainty. Energy Convers. Manag. 2016, 111, 89-102. [CrossRef]

22. Sharifzadeh, H.; Amjady, N.; Zareipour, H. Multi-period stochastic security-constrained OPF considering the uncertainty sources of wind power, load demand and equipment unavailability. Electr. Power Syst. Res. 2017, 146, 33-42. [CrossRef]

23. Nazari-Heris, F.; Mohammadi-ivatloo, B.; Nazarpour, D. Network constrained economic dispatch of renewable energy and CHP based microgrids. Int. J. Electr. Power Energy Syst. 2019, 110, 144-160. [CrossRef]

24. Zhang, Y.; Meng, F.; Wang, R.; Kazemtabrizi, B.; Shi, J. Uncertainty-resistant stochastic MPC approach for optimal operation of CHP microgrid. Energy 2019, 179, 1265-1278. [CrossRef]

25. Luo, Z.; Wu, Z.; Li, Z.; Cai, H.; Li, B.; Gu, W. A two-stage optimization and control for CCHP microgrid energy management. Appl. Therm. Eng. 2017, 125, 513-522. [CrossRef]

26. Dong, J.; Yang, P.; Nie, S. Day-Ahead Scheduling Model of the Distributed Small Hydro-Wind-Energy Storage Power System Based on Two-Stage Stochastic Robust Optimization. Sustainability 2019, 11, 2829. [CrossRef]

27. Wang, Y.; Wang, X.; Yu, H.; Huang, Y.; Dong, H.; Qi, C.; Baptiste, N. Optimal design of integrated energy system considering economics, autonomy and carbon emissions. J. Clean. Prod. 2019, 225, 563-578. [CrossRef]

(C) 2019 by the authors. Licensee MDPI, Basel, Switzerland. This article is an open access article distributed under the terms and conditions of the Creative Commons Attribution (CC BY) license (http://creativecommons.org/licenses/by/4.0/). 